\title{
Metanephric Adenoma
}

\author{
Aneeta Singh Malhotra*, Urvashi Andotra, Harminder kour Rai, Arvind Khajuria, Kuldeep Chander goswami \\ Dept. of Pathology, Acharya Shri Chander College Of Medical Sciences And Hospital, Jammu, India
}

\section{Dear sir}

Metanephric adenoma / renal epithelial tumor are a cortical epithelial tumor with rare incidence of $0.2 \%$ of all epithelial neoplasms ${ }^{1}$. Metanephric adenoma tends to occur more commonly in females with a female:male ratio of $2: 1^{2}$. Tumor is benign ${ }^{3}$ and are typically composed of solid, rare cystic components or calcifications with a poorly derived border ${ }^{4}$. Less than 200 cases have been reported (till 2015) . $^{4}$ Here we report a case of 20 year old female presented with pain right lumber region.

A 20 year old female presented with pain (severe and sudden) right lumber region. On USG and CCET, a tumor involving superior pole of kidney measuring $5 \times 4.7 \mathrm{~cm}$ with central necrosis was identified. Right nephrectomy was done and specimen was sent for histopathologic examination. Grossly the size of the kidney was $11 \times 6 \times 3 \mathrm{~cm}$, a well circumscribed growth measuring $6 \times 5 \mathrm{~cm}$ was identified on the upper pole extending upto the middle.

On microscopic examination, a well circumscribed tumor with small, uniform, closely packed tubules accompanied by scant stroma. Cells were cuboidal with minimal cytoplasm, bland nuclei and uniform chromatin. Focal papillary architecture and glomeruloid bodies were also seen. Psammoma bodies were also seen . rest of the renal

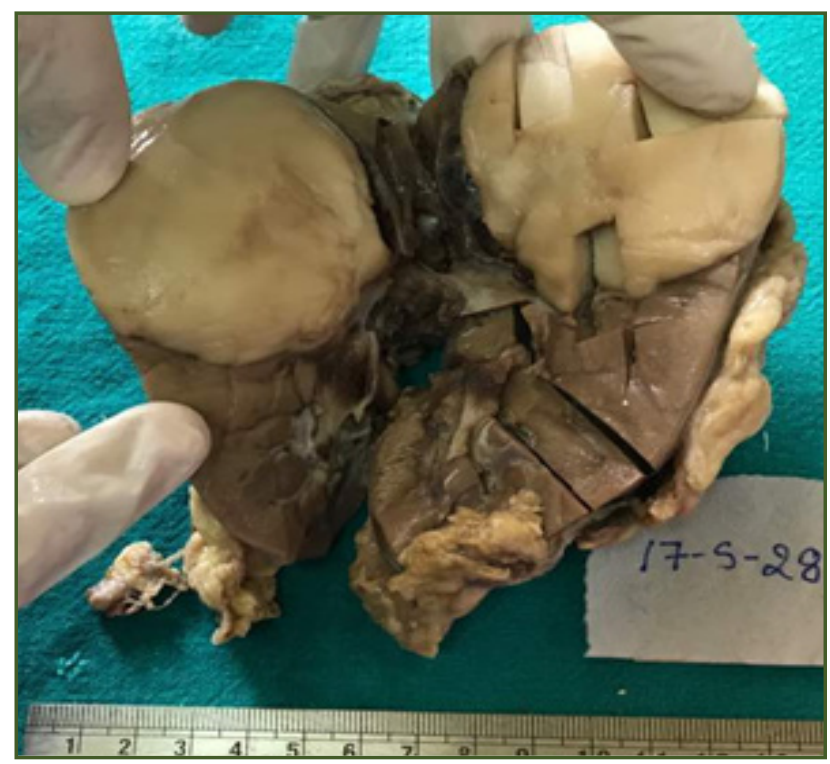

Fig. 1: a well circumscribed growth on the upper pole. tissue appeared normal. All these features were suggestive of metanephric adenoma

Histologically, metanephric adenoma have either sparse fibrous capsule or no capsule at all ${ }^{1}$. Metanephric adenoma overlapse in morphology with epithelial-predominant nephroblastoma in children younger than 12 years and show morphology similar to papillary renal cell carcinoma in adults ${ }^{5}$. Immunohistochemistry plays important role in diagnosis. Metanephric adenoma stains for CD57 and focally for CK $7^{1}$. Though it is benign, few cases of metastatic disease have been reported ${ }^{6,7}$.

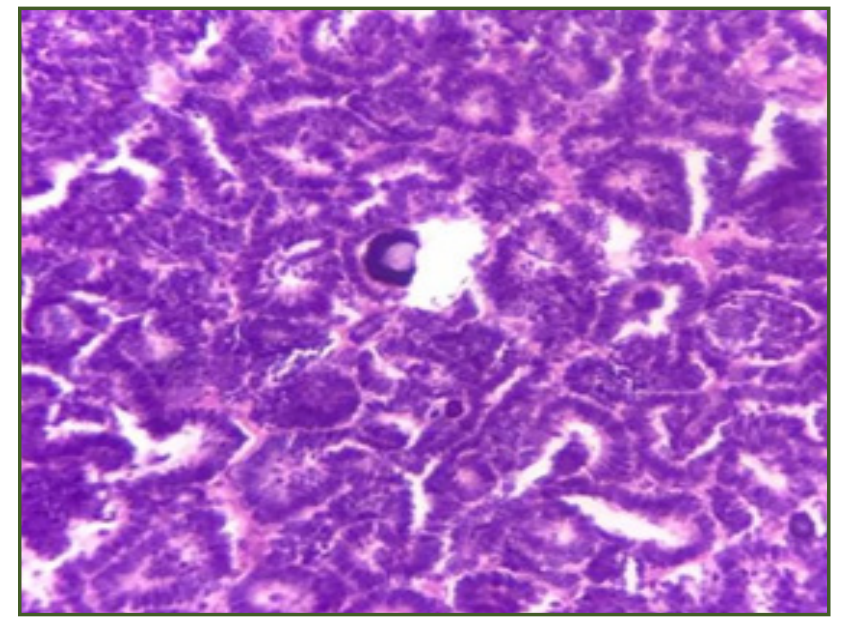

Fig. 2: microscopy, metanephric adenoma with a Psammoma body in the centre.

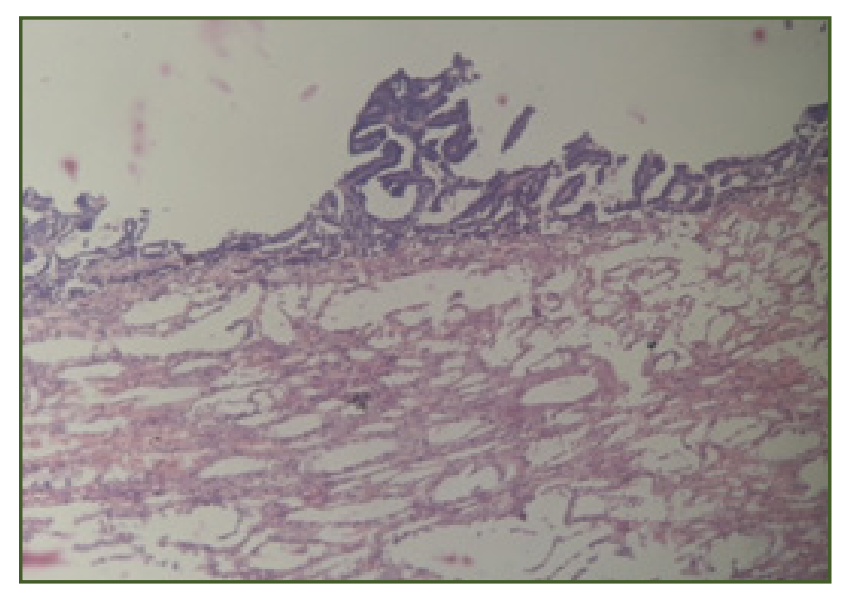

Fig. 3: Focal papillary architecture. 


\section{Reference}

1. Khoo CCK, Khetrapal P, Roux J, Bates AW, Mumtaz F (2014) Metanephric Adenoma: A case report with a Discussion of pathology and follow-up Duration. J Urol Res 1(3):1012.

2. Jinous Saremian, MD, Melanie J Kubik, MD, Shahla Masood, MD.Cytologic features of metanephric adenoma of kidney : Case report and review of literature. Lab Med Spring 2015;46:153-158.

3. Brisigotti M, Cozzutto C. Fabbretti G, Sergi C and Callea F: Metanephric adenoma Histol.

4. Jingtao WU,Qingqiang ZHU, Wenrong ZHU and Hongying Zhang: Metanephric adenoma with diffuse calcifications: A
Case report. Department of medical imaging, Subei people's Hospital, Medical school of Yangzhou, Jiangsu 225001, P.R. china. Onchology letters 10: 1816-1818,2015

5. Modern pathology(2015)28,1236-1248; doi:10.1038/ modpathol.2015.81

6. Pins MR, Jones EC, Martul EV, et al. Metanephric adenomalike tumors of kidney:report of three malignancies with emphasis on discrimating features. Arch Pathol LabMed. 1999; 123:415-420.

7. Nakagawa T, Kanai Y, Fujimotott, et al. Malignant mixed epithelial and stromal tumors of the kidney:a report of the first two cases with a fatal clinical outcome. Histopathology.2004;44:302-4.

*Corresponding author:

Dr. Aneeta Singh Malhotra, Acharya Shri Chander College Of Medical Sciences And Hospital, Jammu, India Phone: +91 9419319454

Email: aneetasinghmalhotra@gmail.com

Financial or other Competing Interests: None. 